\title{
Papers
}

\section{Effect of zinc supplementation on malaria and other causes of morbidity in west African children: randomised double blind placebo controlled trial}

\author{
Olaf Müller, Heiko Becher, Anneke Baltussen van Zweeden, Yazoume Ye, Diadier A Diallo, \\ Amadou T Konate, Adjima Gbangou, Bocar Kouyate, Michel Garenne
}

\begin{abstract}
Objective To study the effects of zinc supplementation on malaria and other causes of morbidity in young children living in an area holoendemic for malaria in west Africa.

Design Randomised, double blind, placebo controlled efficacy trial.

Setting 18 villages in rural northwestern Burkina Faso.

Participants 709 children were enrolled; 685 completed the trial.

Intervention Supplementation with zinc (12.5 mg zinc sulphate) or placebo daily for six days a week for six months.

Main outcome measures The primary outcome was the incidence of symptomatic falciparum malaria. Secondary outcomes were the severity of malaria episodes, prevalence of malaria parasite, mean parasite densities, mean packed cell volume, prevalence of other morbidity, and all cause mortality. Results The mean number of malaria episodes per child (defined as a temperature $\geqslant 37.5^{\circ} \mathrm{C}$ with $\geqslant 5000$ parasites/ $\mu$ l) was $1.7,99.7 \%$ due to infection with Plasmodium falciparum. No difference was found between the zinc and placebo groups in the incidence of falciparum malaria (relative risk 0.98, 95\% confidence interval 0.86 to 1.11 ), mean temperature, and mean parasite densities during malaria episodes, nor in malaria parasite rates, mean parasite densities, and mean packed cell volume during cross sectional surveys. Zinc supplementation was significantly associated with a reduced prevalence of diarrhoea $(0.87,0.79$ to 0.95$)$. All cause mortality was non-significantly lower in children given zinc compared with those given placebo ( $5 v 12, \mathrm{P}=0.1$ ). Conclusions Zinc supplementation has no effect on morbidity from falciparum malaria in children in rural west Africa, but it does reduce morbidity associated with diarrhoea.
\end{abstract}

\section{Introduction}

The annual incidence of malaria is about 300-500 million cases, causing between 1.5 and 2.7 million deaths. ${ }^{1}$ Tropical Africa accounts for $90 \%$ of the morbidity and mortality attributed to malaria; severe disease and death mainly occur among infants in remote rural areas. ${ }^{23}$ Prevailing poverty, lack of functioning health services, climatic and environmental change, and the rapid spread of chloroquine resistance contribute to a deteriorating malaria situation in Africa. ${ }^{1-6}$

Zinc deficiency is common in children in developing countries. ${ }^{7}$ It has been associated with an increased susceptibility to a variety of infections because of its effects on the immune system. ${ }^{8}$ In several studies, mainly from Asia and Latin America, zinc supplementation has been shown to have therapeutic and preventive effects on acute and chronic diarrhoea, dysentery, and pneumonia. ${ }^{9-22}$ Only two studies have provided data on the possible efficacy of zinc supplementation in reducing morbidity from malaria. ${ }^{23}$ We aimed to test the hypothesis that zinc supplementation reduces morbidity from falciparum malaria in African children.

\section{Participants and methods}

\section{Study area}

Our study took place between June and December 1999 in the Nouna district of northwestern Burkina Faso. This area is a dry orchard savanna, populated mainly by subsistence farmers of different ethnic groups. Malaria is a major cause of morbidity and mortality in children in this region, with most transmission occurring during and shortly after the rainy season from June to October.

The main staple food is millet, so children usually receive a diet with little protein. Food intake is particularly low during the rainy season, when workload and disease incidence are high. ${ }^{25}$ As in most of sub-Saharan Africa, zinc supplementation for the control of diarrhoea is not available in Nouna.

\section{Study design}

Our study was designed as a randomised, placebo controlled, double blind efficacy trial. We identified eligible children from the demographic surveillance system of the Centre de Recherche en Santé de Nouna. ${ }^{26}$ Eligible children were aged between 6 and 31 months at enrolment and were permanent residents in 18 of the 39 villages of the study area. We recruited children by lot-

\author{
Department of \\ Tropical Hygiene \\ and Public Health, \\ Ruprecht Karls \\ University, 69120 \\ Heidelberg, INF \\ 324, Germany \\ Olaf Müller \\ clinical epidemiologist \\ Heiko Becher \\ professor of \\ epidemiology and \\ biostatistics \\ Centre de \\ Recherche en Santé \\ de Nouna, Nouna, \\ Burkina Faso \\ Anneke Baltussen \\ van Zweeden \\ general practitioner \\ Yazoume Ye \\ data manager \\ Adjima Gbangou \\ research officer \\ Bocar Kouyate \\ director of research \\ Centre National de \\ Recherche et de \\ Formation sur le \\ Paludisme, \\ Ouagadougou, \\ Burkina Faso \\ Diadier A Diallo \\ epidemiologist \\ Amadou T Konate \\ general practitioner \\ Centre Français sur \\ la Population et le \\ Dévelopement, \\ 75270 Paris, Cedex \\ 06 , France \\ Michel Garenne \\ director of research \\ Correspondence to: \\ O Müller \\ olaf.mueller@urz. \\ uni-heidelberg.de
}

BMJ 2001;322:1-6 
tery (names were drawn blindly at random from a box); 30 from 12 small villages and 60 from six larger villages. Children were allocated zinc or placebo in blocks of 30 ( 15 zinc, 15 placebo) by computer generated randomly permutated codes (prepared by the World Health Organization). We excluded children with serious underlying illness, and we excluded from the final analysis those who were absent from the study area for more than 14 consecutive days. Assuming a mean of one malaria episode per child per season and allowing for $20 \%$ loss to follow up, we used a sample size of 720 children to detect a $20 \%$ reduction in episodes of falciparum malaria with $90 \%$ power $(\alpha=0.05)$.

The children were given $12.5 \mathrm{mg}$ (half a $25 \mathrm{mg}$ tablet) zinc sulphate (Biolectra Zinc, Hermes Arzneimittel, Munich) or placebo daily (except Sundays) for six months. This dose has been recommended by the $\mathrm{WHO}$ and has been used successfully in randomised controlled trials in children in developing countries. ${ }^{9-23}$ The tablets were identical in appearance and taste. They were stored in waterproof plastic tubes labelled with the child's identification number. Fieldworkers based in the villages provided the tablets and were also trained to take finger prick blood samples and to prepare blood films. They were visited twice weekly by supervisors who checked their work, collected completed forms and blood slides, and regularly reported to the study physician based in Nouna (AB). The study supervisors performed random checks of the fieldwork.

The children were seen daily, except for Sundays, by their fieldworker, who took their axillary temperature with an electronic thermometer (Digital Classic, Hartmann, Germany) and filled in a structured questionnaire based on the parents' reported morbidity symptoms of their child, visits to the healthcare providers, and any Western or traditional treatments received. If temperatures were $37.5^{\circ} \mathrm{C}$ or higher, blood samples were taken and thick and thin blood films prepared. If children were sick during the visits the parents were advised to take them to the local health centre.

Three cross sectional surveys were undertaken at baseline (June), mid-study (September), and the end of the study (December). The children were examined by the same physician $(\mathrm{OM})$ during visits. Data on personal characteristics and risk factors (age, sex, ethnicity, use of mosquito nets), clinical data (history, symptoms, temperature, spleen size by Hackett grade, weight, height or length, mid-arm circumference), and parasitological data (thin and thick blood films) were collected from all the children, whereas packed cell volumes and serum zinc concentrations were measured only in random subsamples of 100 children.

\section{Laboratory procedures}

Blood was usually taken by finger prick, and the packed cell volume was measured in the field with a portable microhaematocrit centrifuge (Compur Microspin, Bayer Diagnostics, Germany). Blood films were kept in closed slide boxes until transportation to Nouna (two or three times a week during longitudinal follow up and daily during cross sectional surveys). They were stained with Giemsa at the Nouna hospital laboratory and transported to the Centre National de Recherche et de Formation sur le Paludisme in Ouagadougou for reading. The films were examined by two laboratory technicians and checked by a third investigator in cases of discrepancy. Blood films were analysed for the species specific parasite density per microlitre by counting against 500 white blood cells and multiplying by 16 (assuming 8000 white blood cells per microlitre of blood). If no parasites were seen in 400 fields on the thick film a negative result was declared. A 10\% random sample of blood films was re-examined at the laboratory of the Heidelberg School of Tropical Medicine, showing an overall 97\% concordance for Plasmodium falciparum parasitaemia. Venous blood was kept in a cold box until centrifugation on the same day in Nouna. Serum samples were stored at $-20^{\circ} \mathrm{C}$ until zinc determination at the Heidelberg University laboratory by flame atomic absorption spectrometry (Perkin-Elmer 1100 B, Germany).

\section{Statistical analysis}

Data forms were checked by supervisors before computer entry (version 97, Microsoft Access) at the Centre de Recherche en Santé de Nouna. Parasitological data were entered into EpiInfo (version 6.0) at the Centre National de Recherche et de Formation sur le Paludisme, and the data were transferred to the Centre de Recherche en Santé de Nouna. All data were checked for range and consistency, and all parasitological data and data from cross sectional surveys were double entered. Any differences were resolved by checking against the original case record forms. The randomisation code was broken after the database was closed. Analysis was by intention to treat.

The primary outcome was the incidence of clinical episodes of falciparum malaria (in the presence or absence of $P$ malariae or $P$ ovale $)$. An episode was defined as an axillary temperature of $37.5^{\circ} \mathrm{C}$ or higher with at least 5000 parasites/ $\mu \mathrm{l}$ and no other obvious causes for the fever. This is similar to the case definition used in studies from the Gambia. ${ }^{27}$ Additional definitions of fever and any parasite count and a parasite count of $100000 / \mu \mathrm{l}$ or more were also applied as they represent traditional case definitions for mild and heavy infections.

Secondary outcomes were the duration and severity of falciparum malaria episodes, the prevalence of other causes of morbidity, and all cause mortality. Diarrhoea, fever, and cough were calculated by the number of child days of the respective disease divided by the total number of days of observation. We also investigated the mean species specific prevalences and densities of malaria parasites, mean packed cell volume, mean spleen grade, and mean values for anthropometric measurements during follow up visits for the cross sectional surveys.

The relative risk of falciparum malaria in children supplemented with zinc was calculated as the ratio of incidence densities between the zinc and placebo groups. We defined incidence densities as the number of $P$ falciparum episodes divided by the number of days of observation. Relative risks, $95 \%$ confidence intervals, and $\mathrm{P}$ values were calculated. To exclude recrudescent malaria episodes, the individual observation time was defined as the time interval from the first to last day of observation minus 20 days for each defined episode. In a Poisson regression model we modelled the individual number of malaria episodes as a function of treatment 
with and without adjustment for covariates (age, weight, and height at start of study; sex; ethnic group). In addition, we analysed the effect of treatment on mortality with a proportional hazards regression model both with and without adjustment for covariates. We performed $\chi^{2}$ analysis to test differences in distributions and $t$ tests to compare arithmetic means. All analyses were done with SAS (version 6.12).

\section{Ethical aspects}

We received ethical approval for our study from the ethical committee of the Heidelberg University Medical School and the Ministry of Health in Burkina Faso. The trial was explained to the Nouna health district authorities, the villagers, and the head of each participating compound. Oral consent was obtained from the parents and carers of the children before enrolment. Sick children seen during surveys or visits by the supervisors were treated in the village or referred to Nouna hospital free of charge.

\section{Results}

Of 713 eligible children (one village had only 23 children of the required age group), 709 were enrolled and randomised to either zinc $(\mathrm{n}=356)$ or placebo $(n=353)$. The children were not treated for 4349 days in total owing to absence, an average of 6.3 days per child (2163 zinc, 2186 placebo). Overall, 661 of 685 children $(96 \%)$ were examined during the cross sectional surveys (figure).

Table 1 shows the characteristics of the children at baseline in June. The two groups were similar, except for the children being slightly older in the zinc group (18.7 $v 17.5$ months, $\mathrm{P}=0.03$ ). At baseline $26 \%$ of the children were aged 6-12 months, 27\% were 13-18 months, $26 \%$ were $19-24$ months, and 21\% were $25-31$ months.

The prevalence of malnutrition was high at baseline (table 2), with $36.3 \%$ of children below $-2 \mathrm{z}$ score for height for age (stunting) and $24.6 \%$ below the $-2 \mathrm{z}$ score for weight for height (wasting). The effects of zinc on anthropometric measurements will be published elsewhere.

Serum zinc values paired for June and September were available for 81 children (41 zinc, 40 placebo; table 2). Mean zinc concentrations at baseline were $11.7 \mu \mathrm{mol} / \mathrm{l}$, with no differences between the two groups, and $72 \%$ of the children were zinc deficient according to the reference laboratory's threshold of $13.0 \mu \mathrm{mol} / \mathrm{l}$. After three months (mid-study survey), children in the zinc group had significantly higher serum zinc concentrations than children in the placebo group (15.3 v $12.4 \mu \mathrm{mol} / \mathrm{l}, \quad \mathrm{P}=0.005)$, and the proportion of zinc deficient children significantly declined in the zinc group but not in the placebo group $(11 / 41 v 28 / 40, \mathrm{P}=0.0001)$.

Spleen enlargement (Hackett score $>1$ ) was common at baseline and increased significantly until the end of the study $(87 \%$ in zinc group $v 98 \%$ in placebo group, $\mathrm{P}=0.001$; table 2 ). At the height of the rainy season (September) a quarter of the children reportedly slept under an untreated mosquito net the night before their visit, with no significant differences between the zinc and placebo groups (24\% v 27\%). Parasitological results were available for 511 of 661

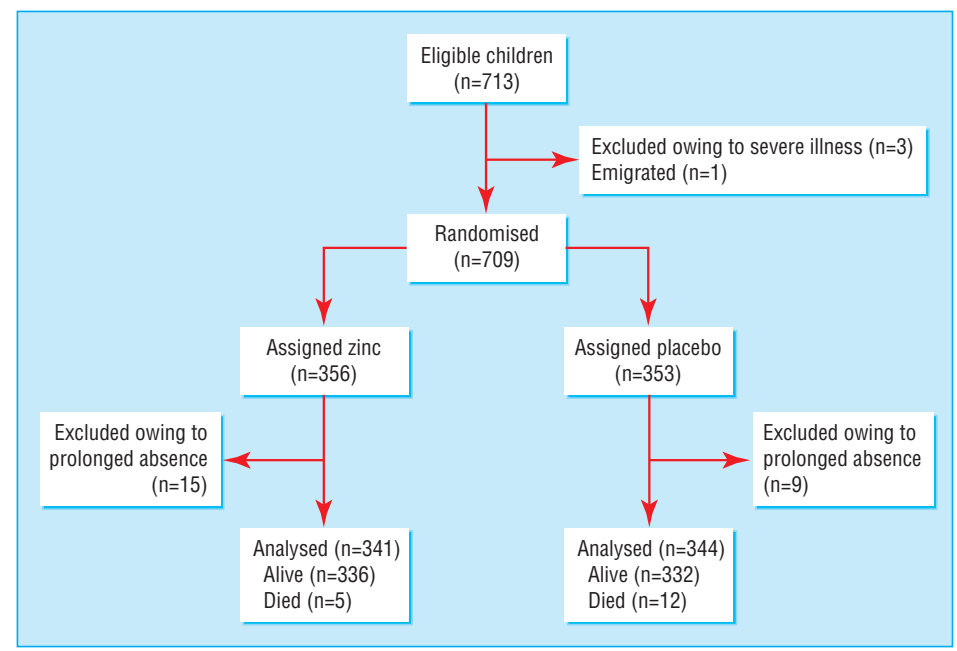

Trial profile

$(77 \%)$ and 615 of $661(93 \%)$ children at baseline and at the end of the study, respectively (table 2). Overall, $P$ falciparum was the most common parasite (99\%), and most of the children who had $P$ malariae $(6 \%)$ and $P$ ovale $(10 \%)$ also had $P$ falciparum. The prevalence of falciparum malaria $(1.4 \%$ in zinc group $v 6.2 \%$ in placebo group, $\mathrm{P}=0.001)$ and of $P$ falciparum, $P$ malariae, and $P$ ovale parasitaemia $(62.8 \%$ v $89.6 \%$, $\mathrm{P}=0.001 ; 4.2 \%$ v $13.2 \%, \mathrm{P}=0.001 ; 0.6 \%$ v $20.2 \%$, $\mathrm{P}=0.001)$, and the mean density of $P$ falciparum $(2909$ $v 7954, \mathrm{P}=0.001)$ increased significantly over the study. Mean packed cell volume values, measured in 70 children (39 zinc, 31 placebo) at baseline and at follow up, significantly decreased from 32.0 to 29.1 over the study period $(\mathrm{P}=0.001)$. No differences were found in clinical or parasitological characteristics between the two groups, either at mid-study (data not shown) or at the end of the study.

Table 3 shows the results for morbidity at follow up in the longitudinal study. Parasitological results were available for 2065 of 2324 (89\%) febrile episodes. Over the six months of the study, the mean number of episodes of falciparum malaria a month was 0.38 (parasite density $\geqslant 1 / \mu \mathrm{l}), 0.28(\geqslant 5.000 / \mu \mathrm{l})$, and 0.02 $(\geqslant 100000 / \mu \mathrm{l})$, with no differences between the zinc and placebo groups at any of the respective three parasite thresholds (relative risk $0.99,95 \%$ confidence interval 0.89 to $1.11, \mathrm{P}=0.94 ; 0.98,0.86$ to $1.11, \mathrm{P}=0.77$; $1.00,0.64$ to $1.60, \mathrm{P}=0.91$ ). This finding remained the same after analysis of the effects of zinc on the incidence of $P$ falciparum by age group (data not shown). No difference was found between the two

Table 1 Characteristics of participants at baseline. Values are numbers (percentages) unless stated otherwise

\begin{tabular}{lcc} 
& \multicolumn{2}{c}{ Baseline } \\
\cline { 2 - 3 } & Zinc group ( $\mathbf{n = 3 3 2})$ & Placebo group (n=329) \\
\hline Mean (range) age (months) & $18.7(6-31)$ & $17.5(6-31)$ \\
\hline Boys & $165(50)$ & $160(49)$ \\
\hline Ethnic group: & $155(47)$ & $149(45)$ \\
\hline Marka & $63(19)$ & $66(20)$ \\
\hline Mossi & $66(20)$ & $64(20)$ \\
\hline Bwaba & $35(11)$ & $42(13)$ \\
\hline Peulh & $13(4)$ & $8(2)$ \\
\hline Others & & \\
\hline
\end{tabular}


Table 2 Clinical and parasitological data at baseline and end of study for cross sectional survey. Values are means (ranges) unless stated otherwise

\begin{tabular}{|c|c|c|c|c|}
\hline & \multicolumn{2}{|c|}{ Baseline } & \multicolumn{2}{|c|}{ End of study } \\
\hline & Zinc group $(\mathrm{n}=332)$ & Placebo group $(\mathrm{n}=329)$ & Zinc group $(\mathrm{n}=334)$ & Placebo group ( $\mathrm{n}=327)$ \\
\hline \multicolumn{5}{|l|}{ Clinical characteristics } \\
\hline Weight $(\mathrm{kg})$ & $8.8(4.9-15.0)$ & $8.6(3.4-15.0)$ & $9.9(5.9-16.1)$ & $9.6(3.9-16.1)$ \\
\hline Height (cm) & $76.1(62-94)$ & $75.4(56-99)$ & $81.0(65-97)$ & $80.2(58-99)$ \\
\hline No (\%) with enlarged spleen* & $272(87)$ & $275(87)$ & $300(97)$ & $288(98)$ \\
\hline No (\%) with temperature $\geqslant 37.5^{\circ} \mathrm{C}^{*}$ & $27(8.1)$ & $16(4.9)$ & $30(9.0)$ & $32(9.8)$ \\
\hline No (\%) with clinical malaria† & $4(1.6)$ & $3(1.2)$ & $18(5.7)$ & $20(6.7)$ \\
\hline Packed cell volume (\%)‡ & $32.6(26-44)$ & $31.7(24-38)$ & $28.6(18-38)$ & $29.7(22-36)$ \\
\hline \multicolumn{5}{|l|}{ Parasitological characteristics } \\
\hline \multicolumn{5}{|c|}{ No (\%) with Plasmodium falciparum density: } \\
\hline$\geqslant 1 / \mu 1$ & $154(60.1)$ & $169(65.5)$ & $287(90.3)$ & $264(88.9)$ \\
\hline$\geqslant 5000 / \mu \mathrm{l}$ & $20(7.9)$ & $31(12.0)$ & $128(40.3)$ & $122(41.1)$ \\
\hline$\geqslant 100000 / \mu \mathrm{l}$ & $0(0)$ & $0(0)$ & $1(0.3)$ & $3(1.0)$ \\
\hline Mean $P$ falciparum density/ $\mu \mathrm{l}$ & 2754 & 3090 & 7602 & 8333 \\
\hline No $(\%)$ with $P$ malariae density $\geqslant 1 / \mu \mathrm{l}$ & $10(4.0)$ & $11(4.3)$ & 46 (14.5) & $35(11.8)$ \\
\hline Mean $P$ malariae density $/ \mu \mathrm{l}$ & 914 & 219 & 674 & 907 \\
\hline No (\%) with $P$ ovale density $\geqslant 1 / \mu l$ & $1(0.4)$ & $2(0.8)$ & $68(21.4)$ & $57(19.2)$ \\
\hline Mean $P$ ovale density/ul & 16 & 345 & 348 & 498 \\
\hline \multicolumn{5}{|l|}{ Zinc measurement§ } \\
\hline Serum zinc $(\mathrm{mmo} / \mathrm{l})$ & $11.5(5.2-27.2)$ & $11.9(5.6-20.5)$ & $15.3(4.8-30.2)$ & $12.4(5.0-27.4)$ \\
\hline
\end{tabular}

*Individuals with missing data were excluded from denominator

†Temperature $\geqslant 37.5^{\circ} \mathrm{C}, \geqslant 5000$ parasites $/ \mu$ l.

łIn paired subsample of 70 children (39 zinc, 31 placebo) at baseline and end of study.

$\S$ In paired subsample of 81 children ( 41 zinc, 40 placebo) at baseline and mid-study.

groups for mean temperature $\left(38.3^{\circ} \mathrm{C}\right.$ in zinc group $v$ $38.3^{\circ} \mathrm{C}$ in placebo group) and mean parasite density (44529 v 44316) during episodes of falciparum malaria $\left(\geqslant 37.5^{\circ} \mathrm{C}\right.$ with $\geqslant 5000$ parasites $\left./ \mu \mathrm{l}\right)$.

Table 3 also shows the effects of zinc supplementation on the number of reported days with other morbidity outcomes. No differences were found in the number of days with fever (relative risk 1.01, 0.95 to

Table 3 Effect of zinc supplementation on febrile episodes of falciparum malaria and other causes of morbidity

\begin{tabular}{|c|c|c|c|}
\hline Morbidity & Zinc group & Placebo group & Relative risk $(95 \% \mathrm{Cl}) \dagger$ \\
\hline Febrile episodes* & (No of children) & & \\
\hline \multicolumn{4}{|c|}{ No of episodes with parasite density $\geqslant 1 / \mu \mathrm{l}$ : } \\
\hline 0 & 26 & 44 & \multirow{6}{*}{$0.99(0.89$ to 1.11$)$} \\
\hline 1 & 116 & 98 & \\
\hline 2 & 128 & 115 & \\
\hline 3 & 51 & 69 & \\
\hline 4 & 19 & 17 & \\
\hline 5 & 1 & 1 & \\
\hline \multicolumn{4}{|c|}{ No of episodes with parasite density $\geqslant 5000 / \mu l$ : } \\
\hline 0 & 69 & 78 & \multirow{6}{*}{$0.98(0.86$ to 1.11$)$} \\
\hline 1 & 138 & 133 & \\
\hline 2 & 104 & 92 & \\
\hline 3 & 24 & 30 & \\
\hline 4 & 5 & 11 & \\
\hline 5 & 1 & 0 & \\
\hline \multicolumn{4}{|c|}{ No of episodes with parasite density $\geqslant 100000 / \mu$ : } \\
\hline 0 & 306 & 310 & \multirow{3}{*}{$1.0(0.64$ to 1.6$)$} \\
\hline 1 & 34 & 33 & \\
\hline 2 & 1 & 1 & \\
\hline Reported symptoms & (child days) & & \\
\hline Fever & 2133 & 2095 & $1.01(0.95$ to 1.07$)$ \\
\hline Cough & 1006 & 949 & $1.05(0.97$ to 1.15$)$ \\
\hline Diarrhoea & 869 & 997 & $0.87(0.79$ to 0.95$) \ddagger$ \\
\hline \multicolumn{4}{|c|}{$\begin{array}{l}\text { Observation time was } 49086 \text { child days for zinc group and } 49021 \text { child days for placebo group; for } \\
\text { analysis of incidence of falciparum malaria, children were removed from numerator and denominator for } \\
20 \text { days after malaria episode. } \\
{ }^{\star} \text { Temperature } \geqslant 37.5^{\circ} \mathrm{C} \text { and specified parasite density. } \\
\dagger \text { Based on Poisson regression model. } \\
\ddagger P=0.002 \text {. }\end{array}$} \\
\hline
\end{tabular}

$1.07, \mathrm{P}=0.62)$ and the number of days with cough (1.05, 0.97 to $1.15, \mathrm{P}=0.22$ ) between the two groups, but the number of days with diarrhoea was significantly lower in the zinc group $(0.87,0.79$ to $0.95, \mathrm{P}=0.002)$.

More children in the placebo group than zinc group died during the study (12 $v 5)$, but this difference did not reach significance. The estimated relative risk in the survival analysis with a proportional hazards model was $0.41(0.15$ to $1.19, \mathrm{P}=0.1)$. The relative risk did not change appreciably (0.47) when covariates were adjusted for.

\section{Discussion}

We found no evidence for zinc supplementation being effective against falciparum malaria in a population of west African children with a high prevalence of malnutrition and zinc deficiency. Recipients of zinc were no different for number of episodes of falciparum malaria or any other malariometric measurement than the recipients of placebo. This was so for all age groups and was consistently seen during both the longitudinal study and the cross sectional surveys.

Our study was a large randomised controlled trial, which had reasonable power to detect a moderate efficacy of the intervention. Case detection was intense and sustained, loss to follow up was small, and individual randomisation made systematic errors unlikely. Dilution of the intervention through fieldworkers mixing up the allocation of zinc or placebo also seems unlikely owing to training and supervision. Moreover, the intervention was followed by a significant increase in serum zinc concentration in the zinc group, whereas zinc concentration remained unchanged in the placebo group.

Our results do not confirm the findings of two community based studies on zinc supplementation and malaria. ${ }^{23}$ One study, on children aged 7-28 months in the Gambia, showed 32\% fewer clinical epi- 


\section{What is already known on this topic}

Zinc deficiency is common in infants in developing countries

Zinc supplementation has been shown to reduce morbidity from infectious disease in such populations, particularly through reductions in morbidity from diarrhoea and respiratory infections

Limited evidence exists for zinc supplementation being effective in reducing morbidity from malaria

\section{What this study adds}

Zinc supplementation has no effect on falciparum malaria in children in rural west Africa

It is effective in reducing morbidity from diarrhoea and may help to reduce mortality from all causes

sodes of malaria in children given zinc compared with those given placebo after follow up over 15 months. ${ }^{23}$ This was, however, a small study on 110 children matched for age and sex, zinc supplementation was given only twice weekly, no information was provided on the methods for diagnosis of malaria, and the effects on malaria were only of borderline significance. The other study looked at the effects of zinc supplementation on morbidity from malaria in 274 children aged 6-60 months in Papua New Guinea. ${ }^{24}$ The children were randomly assigned to $10 \mathrm{mg}$ zinc gluconate or placebo for six days a week for 10 months. The trial reported a $30-35 \%$ reduction in attendances to a health centre due to malaria in those children receiving zinc compared with those receiving placebo.

Even mild zinc deficiency can impair multiple mediators of host immunity. ${ }^{8}$ Some evidence shows that zinc deficiency predominantly affects the cell mediated immune system. ${ }^{28-32}$ In this context, our inability to show an effect of zinc supplementation on morbidity from malaria may provide evidence for cell mediated immunity being less important in malaria in humans. Furthermore, such a hypothesis would be supported by the overwhelming evidence for malaria not behaving as an opportunistic infection in African children with HIV or AIDS. ${ }^{33-35}$

Overall, 17 of the 709 (2.4\%) children died during the study, which confirms the unacceptably high level of childhood mortality from malaria in rural African regions. ${ }^{1-3}$ We found a tendency for zinc to be protective against all cause mortality, which could be a real finding given the known effects of zinc on gastrointestinal and respiratory infections. ${ }^{9-22}$ This is supported by our finding of a significantly lower prevalence of diarrhoea in children given zinc rather than placebo. Our study was not designed to look in detail at the effects of zinc on other causes of morbidity, and such findings must be interpreted with caution.

We thank Walter Fiehn of Heidelberg Medical School for determining the serum zinc values, the team of the Heidelberg Tropical Institute for quality control of the malaria slides, Brian Greenwood for his advice during the design and implementation of the study, the staff of the Centre de Recherche en Santé de Nouna, and the children and their parents.
Contributors: OM was responsible for the overall coordination of the study and contributed to the study design, enrolment and examination of the children, field supervision, and data analysis; he will act as guarantor for the paper. HB was responsible for data analysis and contributed to the study coordination. $\mathrm{ABvZ}$ was responsible for the coordination and supervision of the fieldwork and contributed to the analysis and interpretation of the data. YY was responsible for the management of the data in Nouna and contributed to the design of the study. DAD contributed to the design, field supervision, and laboratory supervision of the study. ATK contributed to the coordination, field supervision, and analysis and interpretation of the data. AG and BK contributed to the design and coordination of the study. MG contributed to the study design and coordination and data analysis. All authors contributed to the writing of the paper.

Funding: The World Health Organization and the Deutsche Forschungsgemeinschaft (SFB 544, control of tropical infectious diseases).

Competing interests: None declared.

1 World Health Organization. World malaria situation in 1994. Wkly Epidemiol Rec 1997;72:269-92

2 Greenwood B, Bradley A, Greenwood A, Byass P, Jammeh K, Marsh K, et al. Mortality and morbidity from malaria among children in a rural area of the Gambia, West Africa. Trans R Soc Trop Med Hyg 1987;81:478-86.

3 Snow RW, Craig M, Deichmann U, Marsh K. Estimating mortality, morbidity and disability due to malaria among Africa's non-pregnant population. Bull WHO 1999;77:624-40.

4 Kilian A, Langi P, Talisuna A, Kabagambe G. Rainfall pattern, El Nino and malaria in Uganda. Trans R Soc Trop Med Hyg 1999;93:22-3.

5 Marsh K. Malaria disaster in Africa. Lancet 1998;352:924.

6 Müller O, Garenne M. Childhood mortality in Africa. Lance 1999;353:673.

7 Gibson RS, Ferguson EL. Assessment of dietary zinc in a population. Am J Clin Nutr 1998;68:S430-4.

8 Shankar AH, Prasad AS. Zinc and immune function: the biological basis of altered resistance to infection. Am J Clin Nutr 1998;68:S447-63.

9 Sachdev HPS, Mittal NK, Mittal SK, Yadav HS. A controlled trial on utility of oral zinc supplementation in acute dehydrating diarrhea in infants. J Pediatr Gastroenterol Nutr 1988;7:877-81.

10 Sachdev HPS, Mittal NK, Yadav HS. Oral zinc supplementation in persistent diarrhea in infants. Ann Trop Paediatr 1990;10:63-9.

11 Sazawal S, Black R, Bhan MK, Bhandari N, Sinha A, Jalla S. Zinc supplementation in young children with acute diarrhea in India. $N$ Engl J Med 1995;333:839-44

12 Sazawal S, Black R, Bhan MK, Jalla S, Bhandari N, Sinha A, et al. Zinc supplementation reduces the incidence of persistent diarrhea and dysentery among low socioeconomic children in India. J Nutr 1996;126:443-50.

13 Sazawal S, Black R, Bahn MK, Jalla S, Sinha A, Bhandari N. Efficacy of zinc supplementation in reducing the incidence and prevalence of acute diarrhea - a community based, double blind, controlled trial. Am J Clin Nutr 1997;66:413-8.

14 Ruel MT, Rivera JA, Santiazo MC, Lönnerdal B, Brown KH. Impact of zinc supplementation on morbidity from diarrhea and respiratory infections among Guatemalan children. Pediatrics 1997;99:808-13.

15 Penny ME, Peerson JM, Marin RM, Duran A, Lanata CF, Lönnerdal B, et al. Randomized, community based trial of the effect of zinc supplementation, with and without other micronutrients, on the duration of persistent childhood diarrhea in Lima, Peru. J Pediatr 1999;135:208-17.

16 Faruque ASG, Mahalanabis D, Haque SS, Fuchs GJ, Habte D Double-blind, randomized, controlled trial of zinc or vitamin A supplementation in young children with acute diarrhea. Acta Paediatr 1999:88:154-60.

17 Roy SK, Tomkins AM, Haider R, Akramuzzaman SM, Behrens RH, Mahalanabis D. Impact of zinc supplementation on subsequent growth and morbidity in Bangladeshi children with acute diarrhea. Eur J Clin Nutr 1999;53:529-34

18 Sazawal S, Black RE, Jalla S, Mazumdar S, Sinha A, Bhan MK. Zinc supplementation reduces the incidence of acute lower respiratory infections in infants and preschool children: a double-blind, controlled trial. Pediatrics 1998;102:1-5.

19 Ninh NX, Thissen JP, Collette L, Gerard GG, Khoi HH, Ketelslegers JM. Zinc supplementation increases growth and circulating insulin-like growth factor I in growth-retarded Vietnamese children. Am J Clin Nut 1996;63:514-9.

20 Rosado JL, Lopez P, Munoz E, Martinez H, Allen LH. Zinc supplementation reduced morbidity, but neither zinc nor iron supplementation affected growth or body composition of Mexican preschoolers. Am J Clin Nutr 1997;65:13-9.

21 Umeta M, West CE, Haidar J, Deurenberg P, Hautvast JGAJ. Zinc supplementation and stunted infants in Ethiopia: a randomised controlled trial. Lancet 2000;355:2021-6.

22 Bhurta ZA, Black RE, Brown KH, Gardner JM, Gore S, Hidayat A, et al of the Zinc Investigators' Collaborative Group. Prevention of diarrhea and pneumonia by zinc supplementation in children in developing countries: pooled analysis of randomized controlled trials. J Pediatr 1999;135:68997.

23 Bates CJ, Evans PH, Dardenne M, Prentice A, Lunn PG, Northrop-Clewes CA, et al. A trial of zinc supplementation in young rural Gambian children. BrJ Nutr 1993;69:243-55. 
24 Shankar AH, Genton B, Tamja S, Arnold S, Wu L, Baisor M, et al. Zinc supplementation can reduce malaria-related morbidity in preschool children [abstract]. Am J Trop Med Hyg 1997;57:249.

25 Sauerborn R, Nougtara A, Diesfeld HJ, eds. Les couts economiques de la maladie pour les menages au milieu rural du Burkina Faso. Frankfurt: Peter Lang Verlag, 1996.

26 Benzler J, Sauerborn R. Rapid risk household screening by neonatal arm circumference: results from a cohort study in rural Burkina Faso. Trop Med Int Health 1999;3:962-74

27 D'Alessandro U, Olaleye BO, McGuire W, Langerock P, Bennett S, Aikins MK, et al. Mortality and morbidity from malaria in Gambian children after introduction of an impregnated bednet programme. Lancet 1995;345:479-83

28 Pekareh RS, Sandstead HH, Jacob RA, Barcome DF. Abnormal cellular immune responses during acquired zinc deficiency. Am J Clin Nutr 1979;32:1466-71

29 Chandra RK, Au B. Single nutritient deficiency and cell-mediated immune responses, I. Zinc. Am J Clin Nutr 1980;33:736-8.
30 Beisel WR. Single nutritients and immunity. Am J Clin Nutr 1982;35:S417-68.

31 Chandra RK. 1990 McCollum award lecture. Nutrition and immunity: lessons from the past and new insights into the future. Am J Clin Nutr 1991;53:1087-101.

32 Beck FWJ, Prasad AS, Kaplan J, Fitzgerald JT, Brewer GJ. Changes in cytokine production and $\mathrm{T}$ cell subpopulations in experimentally induced zinc-deficient humans. Am J Physiol 1997;272:E1002-7.

33 Müller O, Moser R. The clinical and parasitological presentation of falciparum malaria in Uganda is unaffected by HIV infection. Trans $R$ Soc Trop Med Hyg 1990;84:336-8.

34 Butcher GA. HIV and malaria: a lesson in immunology? Parasitol Today 1992;8:307-11.

35 Chandramohan D, Greenwood BM. Is there an interaction between human immunodeficiency virus and Plasmodium falciparum? Int J Epidemiol 1998:27:296-301.

(Accepted 22 March 2001) 